Maria Lourdes Motter

Professora Doutora do Departamento de

Comunicações e Artes da ECA-USP. Pesquisadora do NPTN (Núcleo de

Pesquisa de Telenovela).

\title{
PRODUÇÃO DE SENTIDO: ELO ENTRE COMUNICAÇÃO E EDUCAÇÃO
}

Obra de aubria de Adíson Cilelli percorre das teorias de comunicatéa a análise da educaço no contexto das novas cenologias para esclarecer como a inter-relaça entre ambas tên como cixo a linguagem e a produçăo de sentidos

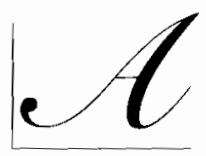

comunicação e a educação, frequientemente constrangidas quando se associam. reintegram-se quando inseridas no amplo espaço que the é próprio: o da linguagem ou da produção de sentidos. Esse pressuposto orienta a obra Comunicação e Educação: a linguagem em movimentol, de Adílson Odair Citelli, e autoriza as considerações que iremos fazer sobre ela. Destaque-se ainda que, na realidade da educação, ambas são campos recortados pelo ensino formal: justapostos, raramente são compreendidos em sua inter-relação.

Seria possível dizer que todo o trabalho tem por meta, enquanto resultado, o esforço de demonstrar a verdadeira função do conectivo e (comunicação e educação). não com o sentido simplificado de aproximação de esferas distintas, mas de elemento unificador de campos que, como outros, as áreas de conhecimento separam e, no curso do tempo, se cristalizam na autonomia artificial dos recortes disciplinadores. De campos especializados, consolidam-se como independentes, rompendo na teoria o que é indissociável na prática: a educação é uma face da comunicação e a comunicação é, em sentido lato, educação.

Retornar à prática geradora da totalidade segmentada passa a ser um processo integrador raramente realizado, seja

1. CITELL_, Adílon Odair. Comunicação e Educação: a linguigẹem em movinento. São Paulo: Editora SENAC. 2.000. $250 \mathrm{p}$. 
como atividade científica, seja como demonstração no domínio da comunicação ou da educação.

É no âmbito da linguagem matrie a um só lempo da comunicaçáo e da educaçánoque o allor vai buscar o elo fundamental.

Para chegar a ela e entrar na sala de aula há um longo percurso teórico por onde desliza o processo no qual se fazem e refazem as teorias da comunicação, as teorias da educação. Estas últimas, inseridas nas políticas públicas marcadas pela descontinuidade de projetos, que produzem fraturas e deixam à deriva os sujeitos do processo educativo: professor e aluno. Estes, por sua vez, olham para direções diferentes, carregam mundos e linguagens que raramente se cruzam pela diversidade de realidades que recobrem.

Voltadas para si próprias, a comunicação e a educação ora se confundem, ora se distanciam, perdendo, progressivamente, sua essência, sua gênese comum e a interdependência de que resulta o seccionamento formal.

\section{I.MGI MGKM EM MOVINENTO}

O livro se estrutura no que poderíamos considerar três grandes blocos: Comunicação (o mundo das técnicas e tecnologias e as teorias da comunicação), Linguagem (as teorias da linguagem, co- municação, produção de sentido, mediações), Educação (contexto geral, realidade do ensino).

Essa estrutura corre paralela à expressão comunicação e educação, onde o primeiro termo (comunicação) dispensa comentários, o segundo, marcado pelo elemento relacional $e$, representa a linguagem enquanto elo dos processos de produção de sentido, e o terceiro (educa(̧ão) refere-se ao termo que deve compor o primeiro. Sem rupturas, preenche-se o espaço que permeia os dois termos numa passagem que recupera a correlação e $o$ vínculo indissolúvel que os ata.

Em nossos comentários, com o objetivo de ressaltar o elemento fundamental contido na obra - que a distingue pelo modo de apreender a história das teorias da comunicação, aproximando-as dos estudos de linguagem e, destas, para a educação no contexto do amplo debate ${ }^{2}$ que se vem produzindo sobre o tema - violentamos seu objetivo ao propor uma nova ordem. Consideramos, em primeiro lugar, a comunicação, passamos à educação e nos detemos na discussão, que julgamos central na relação entre ambas, da linguagem e da produção do sentido. Esse procedimento também vincula-se a um objetivo prático, ou seja, o de sugerir que a obra pode alcançar outros leitores além dos que constituem o leitor ideal do autor, representado pelos leitores que se interessam prioritariamente por um dos termos tematizados: comunicação ou educação, ou ainda, pelo tema relacional linguagem, não tão claramente delimitado a ponto de constituir um bloco. 


\section{COMUNICAÇÃO EM TRÂNSITO}

Nesse cenário, recuperam-se as teorias da comunicação no curso do processo e no deslocamento oscilatório entre a prioridade do pólo da emissão e da recepção, alinhando teóricos que se puseram contra ou a favor dos meios de comunicação, que se preocuparam em estudar seus efeitos, num movimento que privilegiou, por sua vez, cada um dos componentes envolvidos no processo comunicacional ou em aspectos constitutivos desses elementos.

A marca do novo apresenta-se sob a forma de incorporação de autores que, não se enquadrando exatamente entre os teóricos clássicos da comunicação, mantêm com as teorias uma relação de complementaridade ao desenvolver e ampliar estudos aperfeiçoadores dos conceitos de que essas teorias se utilizam. Um bom exemplo vem da introdução de Perelman e Obrechts-Tyteca, com seu Tratado de argumentação ${ }^{3}$, posto que a teoria dos efeitos leva em conta o uso da persuasão, expediente retórico, para promover o convencimento dos receptores e ganhar sua adesão.

$\mathrm{O}$ autor não tem por objetivo fazer desfilar as teoria, mas recolher delas elementos indicadores de convergência para um centro comum e apenas se detém naquelas que oferecem tal possibilidade.

Localizar os estudos centrados num dos dois pólos da comunicação (emissão/recepção) importa para que se possa romper a dicotomia, focalizar um ponto de intermediação e caminhar para o vértice instaurador do princípio de geração dos sentidos, cuja passagem se dá com as teorias das mediações (J. Martín-Barbero) e dos jogos de linguagem (Wittgeinstein).

Do pólo da emissão aos temas compostos como o do agenda setting - em que entre a emissão e a recepção se interpõe a agenda temática, para alguns com características manipulatórias, por funcionar como um filtro na avaliação do que seria ou não interessante para a sociedade -, o deslocamento para o plano da recepção ocorre em sintonia com a revisão do papel do sujeito na história. Seres passivos não combinam com as novas exigências sociais: "o palco italiano cede lugar ao de arena; a catarse aristotélica deixa a cena principal para o distanciamento brechtiano" e, na escola, o aluno ganha a condição de sujeito. Na teoria literária, o leitor passa a elemento fundamental na ordem do discurso. "O texto e seu autor abandonam o terreno solitário da auto-referência para dividir o processo de geração dos sentidos com o leitor, figura até então considerada como 'receptora'".

\section{EDUCAÇÃO EM PROCESSO}

$\mathrm{O}$ segundo bloco se refere ao segundo termo do binômio: a educação, que será pensada em amplitude, no conjunto que a compõe, polimorfo e complexo, detendose no exame de suas principais articulações múltiplas. $\mathrm{O}$ pesquisador pensa a educação detendo-se nas inter-relações que a determinam, ou, para fazer uso de uma expressão do autor, é analisada nas suas interfaces e na hierarquia que pressupõe enquanto instituição que organiza o ensino. Assim, percorre o campo contextualizando-o, discutindo desde concepções mais gerais de caráter filosófico e político, políticas públicas, questões relacionadas até a estrutura burocrática brasileira, verbas,

3. PERELMAN, Chaim e OBRECHTS-TYTECA, L. Tratado da argumentação: a nova retórica. São Paulo: Martins Fontes, 1996. 
políticas salariais, formação profissional, condições em que se dá a prática de sala de aula, a realidade que envolve o professor, o educando, a exclusão.

No balanço resultante, não há culpados ou vítimas irremediáveis. Prevalece o olhar atento e lúcido sobre uma realidade seccionada com precisão cirúrgica e examinada sob múltiplos ângulos para localizar e, a cada passo, dar a conhecer as fraturas que ameaçam todo o sistema educacional brasileiro. Seria melhor, talvez, falar em diagnóstico, uma forma cientificamente madura de ação do pesquisador, um alerta sobre uma situação de crise que clama por intervenção. Não falta apoio em dados ou comprovação de argumentos. $\mathrm{O}$ fundamento e o deflagrador do intenso trabalho de análise vêm à realidade, mostrada pela pesquisa empírica num tempo próximo, com sujeitos concretos de escolas da rede pública da maior cidade da América do Sul.

A pesquisa revela a ausência dos meios de comunicação, e da televisão em particular, da realidade das salas de aula no maior e mais avançado centro urbano brasileiro.

Se é possível localizar o problema na cidade de São Paulo, é o caso de se pensar: como será nos demais estados do Brasil?

Essa pergunta, embebida de obviedade, não está formulada pelo autor que, na linguagem precisa de seu texto, articulada por uma densa argumentação, não se detém nas rimas.
Se também não chega a alcançar a solução, e nem é esse o propósito de seu trabalho, no tocante à questão levantada, identifica e aponta os fatores imbricados na necrose que ameaça o sistema educacional. Observa a imobilidade que cada vez mais distancia o sistema educacional de um mundo que persegue a velocidade da luz, tendo na simultaneidade das comunicações um processo gerador de consequiências para os mais difusos pontos do globo, para o bem ou para o mal, que não podem ser revertidas, nem ignoradas ou, ainda, precisam ser extraídas da complexidade, conhecidas e compreendidas como requisito de mais uma competência.

Os avanços tecnológicos e o cenário de hiper-realidade, construídos pelos sistemas de comunicação e que ora acenam com o paraíso ora ameaçam com o caos, constroem a realidade do presente em sua convivência com outros tempos sociais, como o da educação e em particular da escola, marcam o início do percurso reflexivo do autor. Seu projeto consiste em discutir o binômio comunicação-educação como fenômenos disjuntos, para recuperar o princípio unificador encravado na base comum de sua gênese.

Pensar o sistema educacional reconhecendo o papel fundamental da escola, com suas implicações, torna-se o pressuposto a partir do qual se requisita a atenção para os cruzamentos de estruturas discursivas que aí se verificam, sobretudo pela irradiação advinda das novas tecnologias e dos meios de comunicação: "entender e ajudar a transformar a escola e a sociedade são desafios a serem enfrentados por quem trabalha na interface da comunicação com a educação", posto implicar em procedimentos de reco- 
nhecimento e de redução gradual das "distonias entre as dinâmicas da história e a cristalização do discurso escolar"(p.16).

Se a escola continua sendo o lugar de sistematização e de produção do saber, a "leitura dos sistemas de comunicação, nos componentes de produção, circulação e, sobretudo, de recepção, deve estar integrada aos fluxos críticos-dialógicos dos demais discursos com os quais a escola trabalha"(p.17).

Crítico não no sentido da busca de "fatores de alienação, mentira de classe, manipulação", mas de instauração de "uma prática de busca e entendimento dos processos constituidores dos sentidos, algo comprometido com o encontro das estruturas significativas, sejam elas de puro deleite, prazer difuso provocador do riso, sobriedade analítica ou mesmo a necessária resposta social que pede participação e envolvimentos transformadores" (p.17).

Ao segmentarmos o livro, tínhamos a intenção de demonstrar, dentro dos limites deste comentário, que ele pode atender a interesses imediatos específicos. Ser lido simultaneamente pelo viés da comunicação (primeira parte), ou pelo viés da educação (segunda parte), o que deve violentar as intenções do autor, que aprofundou suas reflexões nos dois temas com o mesmo rigor, dividiu sua atenção entre eles na mesma medida para integrá-los e não para dissociá-los conforme propomos.

Trata-se de uma avaliação pragmática de nossa parte quanto à possibilidade de uso alternativo possível, recomendável e útil, a despeito de um grande prejuízo para o leitor que perde o que a obra tem de essencial, questão de que nos ocuparemos agora: o entre, o trans, o movi- mento de um campo a outro, o traço de união, o significado real e o sentido último do conectivo $e$ como elo entre comunicação e educação.

\section{AMPLIAÇÕES NOS DIÁLOGOS}

Conforme adverte o autor no tópico Comunicação em trânsito, ele não pretende traçar um quadro ou sintetizar visões e perspectivas dos estudos de comunicação, mas recuperar conceitos com o objetivo de localizar "as variáveis mais estimulantes" para a ampliação dos diálogos com o campo educativo "pensado de forma dominante em sua vertente formal"(p.21).

Considerando que os estudos de comunicação levaram à "absolutização de aspectos de um processo cujas faces vivem em tensas relações", o autor introduz no debate sobre a circulação dos discursos, em particular dos "massivos", a noção de "jogo dialogal".
Ele localiza a questão da produção dos sentidos na instância que preenche o espaço situado entre a emissão e a recepção dos discursos.

Ou ainda entre enunciador e enunciatário, onde se pode apreender a natureza dos "procedimentos dialógicos e interativos".

A "categoria dialogal" permite passar das técnicas que possibilitam as trocas verbais para "o terreno que dá existência aos sistemas de composição e representação da linguagem"(p.54). 
Inspirando-se em M. Bakhtin ${ }^{4}$, diz Citelli: "Consideramos, agora, a existência de um espaço dialogal por onde transitam os signos, produtos materiais que permitem a elaboração e o reconhecimento das várias modalidades significativas. Postos no entre, os signos serão animados não só por experiências do sujeito (...) mas por cadeias históricas, coletivas, que nele vão deixando suas marcas à maneira dos icebergs redesenhados ao longo de sua trajetória marinha" (p.57).

A concepção de signo, do teórico russo, nascida na década de 20 e iluminada para o Ocidente, a partir dos anos setenta, já pressupunha a interação entre sujeitos, determinando, no processo subjetivo, no espaço mesmo da relação entre eles, o lugar da produção do sentido. Desse modo, dava à comunicação ou ao processo comunicativo a ampla e precisa dimensão que só iria ser adequadamente avaliada no contexto das teorias da linguagem em anos bem recentes.

As questões postas em sua obra, Marxismo e filosofia da linguagem, rendem um profícuo e intenso debate que está longe de se esgotar, sobretudo se considerarmos as áreas conexas do conhecimento que seu pensamento alcança, abrangendo a Lingüística, a Teoria da Literatura, a Psicologia Social, os Estudos Culturais. Elas permitem repensar tais domínios e ainda pensá-los no presente, envolvido este no tramado denso das comunicações, entendidas enquanto entrelaçamento de aparatos tecnológicos, multiplicidade de linguagens e códigos, incluídos os das máquinas e o dos grupos e subgrupos humanos.
Ler o mundo com Bakhtin é pensá-lo a partir do signo enquanto objeto material, social e concreto constitutivo da consciência humana.

Assim, ao sintetizar os pressupostos básicos do autor, Citelli lembra que "...os interesses, conceitos, ideologias, visões de mundo podem ser reconhecidos nos discursos postos em movimento pelos sujeitos. As palavras, as frases e os textos registram, sob diferentes circunstâncias, os modos através dos quais as experiências são representadas. Ler o signo é ler a consciência"(p.58).

Outro pressuposto refere-se ao caráter dialógico e polifônico da linguagem e afirma que a fala individual expressa vozes sociais. "A voz diz a permanência das apropriações do material coletivo, derivando, em suas elaborações particulares, para o campo da paráfrase, da paródia, da estilização etc." Resulta que é possível reconhecer, através dos signos, as marcas de falas ou vozes que se misturam nos enunciados postos em movimento. Pois, “... ao falarmos exercitamos, a rigor, discursos quase sempre incorporados no deslocamento, malgrado imaginarse o exercício da novidade e o pleno domínio sobre o que se diz"(p.58).

Há ainda o pressuposto que diz respeito ao caráter social e ideológico do signo/linguagem. "A expressão simbólica ou representativa dos conceitos, preconceitos e valores resulta da convivência dos sujeitos com elementos materiais que ganharam e ganham sentido exatamente nos embates 
coletivos"(p.58). O aspecto ideológico participa tanto da constituição da linguagem, como atua estimulando e alimentando as mais importantes experiências humanas. Neste caso, diálogo não significa acordo mas pode se traduzir em troca ou complementaridade, oposição ou choque.

Citelli retoma também a crítica de Bakhtin $^{5}$ à teoria lingüística de F. Saussure, o pai da Lingüística moderna. Quem fala é o próprio Bakthin "a verdadeira substância da língua não é constituída por um sistema abstrato de formas lingüísticas, nem pela enunciação monológica isolada, nem pelo ato psicofisiológico de sua produção, mas pelo fenômeno social da interação verbal, realizada através da enunciação ou enunciações. A interação verbal constitui, assim, a realidade fundamental da língua"(p.59).

Consideramos a citação o ponto em que linguagem e comunicação se unificam ao se ligarem geneticamente na produção do sentido ou dos sentidos, ponto de chegada das buscas de Citelli. Diz ele: "a citação é exemplar porque sintetiza a discussão sobre o problema do diálogo e da produção dos sentidos. Novamente, deve-se remeter a comunicação verbal para aquele 'intervalo social' em que as distintas enunciações e as falas passam a viver em tensão permanente"(p.59).

A despeito da centralidade da linguagem verbal, ao tomar o signo como convergência do social, do ideológico e a enunciação como realidade da comunicação, permite a extensão de seus conceitos a todos os sistemas de signos. Nessa perspectiva, sua contribuição para o estudo dos fenômenos que envolvem a produção e a circulação dos sentidos ganha aplicação e mostra sua atualidade, sobretudo em se tratando dos modernos meios de comunicação - entendidos no seu conjunto e nas suas inter-relações - como o cinema e a televisão, por exemplo.

A aproximação com autores latinoamericanos como Jesús Martín-Barbero e Guillermo Orozco Gómez, se faz em decorrência do espaço da produção dos sentidos, que enseja a introdução de teorias sobre as mediações e os mediadores. Desloca-se a discussão dos fluxos da comunicação de massa, ou massiva, na concepção desses autores, dos meios para as mediações da cultura. Assim é que as visões de mundo dos grupos decorrem das "intermediações promovidas pela família, pelas sociedades amigos de bairro, pelos partidos políticos, por permanências discursivas diversas", que podemos entender como memória, o que entra em tensão com a fala das mídias, ficando a compreensão e a interpretação das mensagens dos meios "dependentes de ajustes os mais amplos que os receptores/destinatários conseguirem" (p.62).

Nessa linha de reflexão o autor explica: "o campo de abrangência das pesquisas comunicacionais passa a ser, portanto, sócio-histórico e busca investigar os fluxos dialógicos massivos. MartínBarbero afasta a idéia de que a cultura popular reproduza de forma direta e unilateral esquemas alienados decorrentes de procedimentos manipuladores exercidos diretamente pela mídia. O que está em jogo são as novas condições de existir e manifestar a sociabilidade no mundo onde se evidenciam expedientes diferenciados de construir esquemas hegemônicos" (p.62). 
Ao retomar a assimetria entre 0 monologismo praticado na escola e o dialogismo, o autor faz a aproximação de Bakhtin com o educador Paulo Freire.

A partir da base comum das discussões empreendidas, por Paulo Freire, na prática pedagógica; e por Bakhtin, no âmbito geral da linguagem, onde estão implicados conceitos como o de diálogo e o de interação. Diz Citelli: "Se existe em nosso autor (Paulo Freire) uma teoria do conhecimento, um método educativo e uma visão da história, há também, ainda que formulado com outras tintas, um conceito de linguagem que supera tanto o nominalismo empirista como o subjetivismo expressivo. E, nesse sentido, é interessante observar que Paulo Freire e Mikhail Bakhtin, malgrado as distâncias e seus campos mais específicos de trabalho, tenham estabelecido nos pressupostos dialógicos e interacionistas os pontos fortes de uma epistemologia envolvida no compromisso de construir sujeitos mais livres e identificados com procedimentos democráticos”(p.133).

O panorama do mundo contemporâneo leva o autor a repensar a assimetria entre este e o ensino formal, a entender e a demonstrar que o educando desenvolve, nesse contexto, um novo modo de percepção da realidade. Modo este ainda não levado suficientemente em conta a ponto de se adequar o trabalho em sala de aula às novas exigências do mundo transformado e em transformação. Caracterizase, assim, o que o autor denomina "distonia entre o discurso pedagógico formal e o informal mediático". A interação e o dialogismo, requeridos para dar espaço aos cruzamentos discursivos no amplo espaço do cotidiano social, ainda esbarram no monologismo escolar. A voz institucional reproduz sentidos cristalizados, enquanto o educando convive, ilhado, despreparado, com um mundo em progressiva complexidade polissêmica, onde os meios de comunicação ganham prevalência na produção de sentidos e podem concorrer, com vantagem, com o discurso escolar. "Ler as várias modalidades de signos passa a ser, também, uma questão afeita ao espaço escolar (...). As lógicas orientadoras do discurso pedagógico na sala de aula, caso sejam processadas fora do circuito reificado e do puro ajustamento, devem obedecer aos ritmos e andamentos que, ao elegerem o tempo analítico e reflexivo como matéria pulsante, reconhecem as possibilidades de matizar significados e indagar acerca dos sentidos produzidos" (p.147).

\section{DIÁLOGO ABERTO}

Manifestamos aspectos de nossa leitura que poderão não ser os mais relevantes do trabalho do pesquisador/autor, mas que correspondem a um diálogo que cada leitor terá que empreender por si mesmo. Tampouco seria possível uma tal capacidade de síntese que desse conta em poucas páginas de tão vasto universo - complexo na sua multiplicidade de focos e no rigor da revisão teórica. Reconhecemos nossa irreverência ao sugerir a cisão da obra para leitura setorizada, sinalizando as possibilidades de seu aleance.

Resta ainda o exercício da prática dialógica no sentido da complementaridade. Trata-se de atenuar um comentário 
do autor quanto ao peso atribuído aos mecanismos que forçaram a inclusão de temáticas sociais na telenovela. Embora nos limites de apenas um exemplo, de um pequeno e pouco expressivo detalhe no contexto da obra, em meio à discussão da teoria dos "efeitos controlados" lamos por excessivo rigor e com o objetivo de redimensionar o valor sêmico da expressão utilizada ("forçou"). Assim, o leitor poderá também ser remetido para trabalhos que se dedicaram ao estudo desse produto ficcional ${ }^{7}$, nos quais se procurou demonstrar que temáticas como a de $O$ rei do gado nascem, desenvolvem-se e tomam forma artística, a partir das vivências e inquietações do autor no curso de sua vida. Fazemos tal observação

Resumo: A autora comenta o livro Comunicação \& educação - a linguagem em movimento, de Adilson Citelli, ressaltando como o autor faz o percurso das teorias de comunicação à análise da educação no contexto das novas tecnologias, destacando a necessidade de a escola desenvolver mecanismos que propiciem a inter-relação das linguagens utilizadas por cada um desses campos. Analisa como a obra dá a chave para que o leitor compreenda a conexão entre comunicação e educação através do jogo dialógico da construção de sentidos, permitido pela linguagem verbal, dando relevância às contribuições de Mikhail Bakhtin em relação, principalmente, à concepção de interação verbal, pois é ela, enquanto realidade fundamental da lingua, que materializa o processo comunicativo e educativo.

Palavras-chave: comunicação e educação, interação verbal, dialogismo, teorias da comunicação, escola para que não se entenda que seus roteiros se elaboram a partir de imposições do meio de comunicação para o qual produzem. Pode-se lembrar que a telenovela Pantanal só foi realizada muito tempo depois de escrito o roteiro, já trazia o tema da terra e continha embrionariamente a questão do sem-terra, que também apareceu em Renascer, e, finalmente, ocupou a centralidade na telenovela citada.

Apenas para concluir, devemos acrescentar que comunicação e educação devem estender e ampliar suas relações discursivas para que a escola possa interagir dialogicamente - em situação de sala de aula com as linguagens que envolvem o mundo, que por sua vez, envolvem o professor e principalmente $o$ aluno.

Abstract. The author comments on Adilson Citelli's book Comunicação \& educação - a linguagem em movimento (Communication \&Education - language in movement), emphasizing how the author traces the communications theories all the way through the analysis of education in the context of the new technologies, stressing the need for the school to develop mechanisms that propitiate the interrelation of the languages used by each of these fields. An analysis is made of how this work is a key for the reader to understand the connection there is between communication and education through the dialogic game of building senses, allowed for by verbal language, giving relevance to Mikhail Bakhtin's contribution regarding, most especially, the verbal interaction conception since it is it that, while being the language's fundamental reality, materializes the communicative and educative process.

Key words: communication and education, verbal interaction, dialogize, theories of communication, school

6. Diz o autor. "o two-step flow (fluxo em dois níveis) que evidencia o movimento discursivo que surge em níveis, graus, instâncias e momentos de circulação dos assuntos entre o locus transmissor e as intervenções dos líderes de opinião. De certo modo não é só a Globo que mostra o problema da luta pela posse da terra tendo por veículo a telenovela $O$ rei do gado (...). O reconhecimento dessa circulação, que não se ajusta mais ao one-step flow (fluxo de um nível), forçou a inclusão de temas sociais na estrutura das telenovelas, em alguns casos até sob orientação de organismos como o Population Communication International" (p.44).

7. Aqui remetemos o leitor para os trabalhos no Núcleo de Pesquisa de Telenovela - NPTN, do CCA-ECA-USP, entre eles o de MOTTER, M. L., Ficção e realidade: a construção do cotidiano na telenovela. Tese de livre-docência. São Paulo, ECA-USP, dez/1999. (mimeo.)/(N.E.d) 